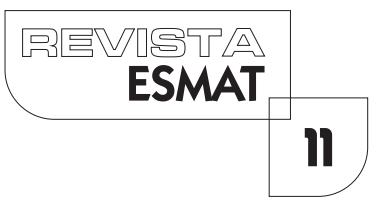

\title{
AS NORMAS SOCIAIS COMO INSTRUMENTO DE PROTECÇÃO DOS DIREITOS HUMANOS
}

SOCIAL RULES AS INSTRUMENT FOR HUMAN RIGHTS PROTECTION

Rute Saraiva

Professora Auxiliar da Faculdade de Direito de Lisboa.E-mail: rutesaraiva@fd.ul.pt

\section{RESUMO}

Na luta pela afirmação e protecção eficiente e eficaz dos direitos humanos, a abordagem tradicional estritamente jurídica pode revelar-se insuficiente e amiúde até desadequada. Assim, procura-se junto da ordem normativa social, tantas vezes menosprezada pela elite jurídica, uma via alternativa dotada de maior realismo e flexibilidade. Afinal, procurase a alteração de comportamentos individuais, sociais e institucionais moldados pelo enquadramento de um determinado ambiente socio-cultural que importa ponderar. Em suma, pressupõe-se aqui o enfoque social na fonte da conduta como chave para uma efectivação mais sustentada dos direitos humanos.

PALAVRAS-CHAVE: Normas sociais; Instrumentos de protecção; Direitos humanos.

\section{ABSTRACT}

The traditional and strictly legal approach for the affirmative, efficient and effective protection of human rights might be insufficient and sometimes even unsuitable. Therefore, we pursue a more realistic, flexible and alternative solution based on a normative social order, so often despised by elite lawyers. After all, we aim for changes in individual, social and institutional behaviour influenced and framed by a certain socialcultural environment that must be accounted for. In sum, we presume a social focus of the behaviour as a key for a more sustainable effectuation of human rights.

KEYWORDS: Social Rules; Instruments of protection; Human rights. 
As páginas que se seguem constituem uma pequena provocação à perspectiva hegemónica e quase totalitarista do Direito e dos advogados mainstream dos direitos humanos que vêem na ordem jurídica, em especial na lei e nos tratados internacionais, a melhor, se não a primeira ou única forma de garantir a sua protecção tanto no plano nacional como internacional. $\bigcirc$ objectivo assumido é pois de demonstrar a falácia desta assunção e revigorar novas abordagens para a efectivação dos direitos humanos, reabilitando, em especial, o recurso às normas sociais, tantas vezes discriminadas e desconsideradas nas academias e instituições públicas sobretudo nos países de tradição romano-germânica como Portugal. Alerte-se porém, desde já, que tal não significa que se defenda a sua supremacia ou a substituição global dos actuais instrumentos jurídicos pela ordem social. Apenas se pretende um maior realismo e adequação na garantia dos direitos humanos graças a uma flexibilização dos instrumentos utilizados.

Com efeito, a protecção e implementação efectivas dos direitos humanos obrigam a uma mudança de comportamento tanto dos indivíduos como de instituições colectivas fundamentais como o Estado, as empresas ou as famílias que reflectem uma determinada cultura e ambiente social que devem, necessariamente, ser equacionados. Compreender a importância do contexto situacional e das narrativas sociais constitui uma ferramenta preciosa para perceber alguns dos mecanismos condicionadores das condutas reais e assegurar, de forma sustentada, o cumprimento dos direitos humanos. Querer mudar a adesão interna a uma norma (dever ser) sem atender ao elemento externo modulador pode revelar-se, no fim, uma tarefa onerosa e até infrutífera. Mais julgar comportamentos em absoluto, dissociados do contexto, pode igualmente consubstanciar uma distorção injusta dos factos. As atrocidades cometidas na Alemanha nazi ou no Ruanda são paradigmáticas. Poucos acreditarão na macabra coincidência da população inteira de um país ser, num determinado momento, composta por psico e sociopatas. Em suma, aceitando que existiria, em ambas as situações, apenas um punhado de indivíduos verdadeiramente "maus", a explicação poderá parcialmente passar por um fenómeno de cegueira social, de alteração do padrão de referência (âncora) social ou por uma dissonância entre a norma pessoal e social percepcionada por questões de pura sobrevivência. Por outras palavras, o ambiente e ordem social condicionam os comportamentos. Ora esta abordagem difere do discurso típico dos direitos humanos (em que a violação e o acatamento são assumidos como uma disposição e responsabilidade individuais) ao se pressupor o enfoque social na fonte da conduta.

Reconhecendo que o homem é um ser associal social, com uma predisposição mais vincada para a sociabilidade do que para o isolamento (até por questões evolucionárias e de sobrevivência da espécie), estranho seria não olhar para as dinâmicas de grupo, designadamente a sua formação e as relações intra e extra-grupo, e para as normas sociais enquanto instrumento normativo tanto complementar, como sucedâneo como contrário ao Direito. Perceber estas interacções entre o jurídico e o social (e até com 
outras ordens normativas como a moral ou religião) deveria representar uma das linhas de investigação prioritárias das ciências sociais pelo potencial de eficácia e eficiência na alteração e conformação comportamental.

No plano dos direitos humanos, três grandes questões podem beneficiar desta perspectiva holista e integrada:

I.Perceber a razão das violações dos direitos humanos: porquê e como agem e como acham que devem agir os indivíduos, expondo e explorando, nomeadamente, possíveis dissonâncias entre o elemento descritivo e o deontológico. Veja-se, por exemplo, o caso da prática do "fanado" (mutilação genital feminina) na Guiné Bissau que revela uma tensão entre a defesa dos direitos humanos e o respeito pela tradição cultural,' em que apesar de a excisão ter sido criminalizada, a sua execução em violação da lei parece aos olhos da população de origem muçulmana, em particular rural, menos grave do que a violação da tradição. Aos seus olhos o estigma social que as suas filhas sofrerão ao serem consideradas impuras por não terem sido excisadas sobrepõe-se ao receio de penalização jurídica, tendo nos últimos anos conduzido a que a prática, que se mantém, passasse a ser feita às escondidas (em vez das festas públicas anteriores) em crianças cada vez mais novas e em piores condições de salubridade. Por outras palavras, a norma jurídica não colou como desejado, revelando o carácter "pegajoso" das normas sociais.

2.Perceber quais os mecanismos sociais que podem potenciar a efectiva garantia dos direitos humanos. Mormente, na hipótese de normas sociais algo enraizadas contrárias ao Direito dos direitos humanos poderá ser importante a sua desmontagem interna e não por imposição externa, na senda das dinâmicas in group. Em Marrocos, o papel do Rei Mohammed VI no desenvolvimento dos direitos das mulheres representa um exemplo paradigmático de transformação endógena, ademais alimentada por um líder, numa abordagem de cima para baixo. ${ }^{2}$

3.Possibilitar a tradução e a adaptação das normas jurídicas quando se lida com culturas muito diferentes. Na questão indígena, em particular quanto à ocupação do seu território, é notória a divergência conceptual e de linguagem, chocando a sua visão holista socio-ambiental de si mesmos e da terra com o direito de propriedade entendido por fazendeiros ou grandes empresas. $\bigcirc$ recurso às normas sociais, que aliás Ostrom demonstrou nos seus trabalhos serem peças fundamentais no

'O direito à cultura não deve ser confundido com a protecção da tradição, já que aquele exige que haja uma possibilidade de escolha de aderir ou não.

${ }^{2}$ J. Jütting e C. Morrisson (2005). 12. 
equilíbrio socio-ambiental, poderá servir de chave para a construção de pontes de entendimento e de transição e posteriormente até de integração entre a arquitectura normativa indígena e de matriz romano-germânica. A um nível diferente, recorde-se que este tipo de abordagem foi aplicado com sucesso pelos primeiros cristãos ao aproveitarem e darem novas roupagens às festas pagãs, promovendo a adesão à sua dogmática.

A proposta de abertura às normas sociais difere pois da perspectiva legalista e positivista típica dos direitos humanos e do Direito internacional dos direitos humanos, cuja efectividade se vê, aliás, afectada pelos problemas inerentes à fragilidade resultante da inexistência de um sistema coercivo eficaz. Afinal, em última linha, a sua aplicabilidade depende da coercibilidade interna dos Estados; o poderio militar, político e económico dos Estados ainda determina a sua sujeição a sanções no caso de violação da ordem jurídica; nem todos os Estados aderem à jurisdição dos tribunais internacionais; e a intervenção do Tribunal Penal Internacional é, por definição, tardia, isto é posterior à violação dos direitos humanos. Ora, se o Direito não é suficiente, há que desafiar o entendimento supremacista e preconceituoso do Direito em relação às outras ordens normativas, introduzindo, quanto mais não seja na ciência jurídica, e no Direito internacional dos direitos humanos em particular, os ensinamentos da sociologia e da psicologia cognitiva e social.

Antes de avançar, porém, uma dúvida prévia coloca-se: será a lógica da ordem social e das dinâmicas de cognição social e de grupo aplicáveis a pessoas colectivas como Estados ou empresas? ${ }^{3}$ Afinal, a abordagem social tem sido pensada no plano individual. No fundo, até que ponto uma entidade plural consegue internalizar uma norma? De forma telegráfica, uma vez que não será esta a melhor sede para aprofundar a questão, não só as pessoas colectivas são feitas de pessoas, que tomam as decisões, como vários dados empíricos revelam um paralelismo no comportamento das pessoas singulares e colectivas. Por exemplo, estas também parecem sentir vergonha. Basta recordar o sistema de encapotamento do aprisionamento de possíveis terroristas pelos Estados Unidos, com voos e prisões secretas e violentas como Abu Ghraib, ${ }^{4}$ ou de esconder trabalho infantil em fábricas deslocalizadas por parte de multinacionais.

Importa então começar por definir as normas sociais, cuja distinção com outro tipo de normas (jurídicas, religiosas, morais) nem sempre é fácil, por vezes sobrepondo-se. Esta é, aliás, mais uma razão para a sua utilização, ainda que urja compreender as forças e situações que motivam efeitos de contradição e expulsão (crowding out) e de reforço (crowding in) para uma aplicação combinada mais eficaz e eficiente.

${ }^{3}$ R. Goodman e D. Jinks (20 I2). 16- I7; S. Gopolan (2007). 806.

${ }^{4}$ S. Gopolan (2007). 
De acordo com Ellickson, ${ }^{5}$ entende-se por normas sociais regras que regem o comportamento individual e que são impostas difusamente por terceiros, que não o Estado, através de um sistema de sanções ou de recompensas sociais, que incluem, entre outros, indignação, repúdio, vergonha, estigma, expulsão, pedidos de desculpa ou prémios e louvores. Esta definição atende essencialmente ao elemento objectivo da norma social, isto é a uma prática e repetição de atitudes partilhadas e aplicadas sobre como comportar-se em grupo, normalmente associadas, no seio de vária doutrina jurídica, a assuntos menores. Há que atender igualmente a um elemento subjectivo, pouco explorado, associado à internalização da norma. ${ }^{6}$

Numa comparação com as normas jurídicas, as normas sociais revelam-se menos explícitas e formais mas mais difusas e descentralizadas, o que lhes confere um enorme poder e capacidade de intrusão.

As normas sociais, enquanto representações mentais de base social decorrentes da interacção social e de dinâmicas ligadas a fenómenos de identidade e reciprocidade, podem ser descritivas ou injuntivas. As primeiras, ligadas ao elemento objectivo, traduzem crenças quanto à conduta concreta de outros (ex. achar que os outros excisam as suas filhas) e reportam-se pois às condutas em si, ao que é. Já as segundas, associadas em boa parte ao elemento subjectivo, revelam a crença sobre o que outrem pensa que deveria ser feito e incluem, consequentemente, a ameaça de uma sanção; por outras palavras reportam-se ao que deveria ser. Na verdade, nem sempre os dois tipos de normas coincidem até por causa de problemas de percepção do socialmente correcto, designadamente associados a estereótipos ou à sobreavaliação da uniformidade do grupo, que potenciam fenómenos de extremismo e polarização. Vejase, por exemplo, o caso de se assumir que, porque se observa uma determinada conduta, deverá ser assim que se deve comportar mesmo que, na prática, não se acredite naquele acto ou que não seja o que socialmente se faz. A dissonância é paradigmática nas situações de ignorância pluralística ${ }^{7}$ em que os indivíduos consideram que o comportamento que observam por parte dos outros traduz o que privadamente sentem e pensam, concluindo que não estão alinhados com os outros quando tal pode não ser verdade. No fundo, subestimam-se as limitações comportamentais decorrentes do espartilho social.

Com efeito, as pessoas tendem a esconder os seus comportamentos normativos que julgam divergentes dos socialmente aceites e a revelar mais os comportamentos normativos que vão no sentido de serem socialmente aceites, da mesma forma que mais facilmente exprimem opiniões que acham ser consistentes com as normas sociais percepcionadas ou que apenas se desviam um pouco da norma injuntiva (ex. pertencer

\footnotetext{
${ }^{5}$ R. C. Ellickson (200I).

${ }^{6}$ S. Gopolan (2007). 813-8|4.

${ }^{7}$ D.A. Prentice (2012). 10.
} 
a um grupo que apoia os direitos das mulheres mas ser mais ou menos radical na sua aplicação, veja-se apoiar a liberdade de abortar ou a remuneração do trabalho doméstico). ${ }^{8}$

Em suma, nem sempre o comportamento público e social coincide com a opinião privada, o que suscita um problema de ilusão de escolha, ${ }^{9}$ em especial, e paradoxalmente, em sociedades ditas democráticas, uma vez que aqui mais facilmente se assume que o comportamento social corresponde à crença privada. No entanto, o mesmo realça que pode ser mais fácil do que parece à primeira vista quebrar uma norma social que, nomeadamente, viola um direito humano. Afinal, a norma privada pode ser consentânea com a protecção do direito e a norma social o produto de uma má interpretação ou percepção do que se pretende.

Esta dissonância, que pode ser explorada para potenciar o respeito pelos direitos humanos, pode derivar de três principais causas.

Em primeiro lugar, do peso do papel social que se acha que se tem de desempenhar. Por exemplo, na relação guarda prisional-prisioneiro, marido-mulher, fazendeiroíndio. ${ }^{10}$ Recorde-se igualmente o caso de dissonância a respeito da política segregacionista nos Estados-Unidos, em que mesmo nos estados do sul a maioria da população não declarava nem revelava nos seus comportamentos privados concordância com a prática racista. Veja-se porém que, pese embora, o potencial de correcção dos comportamentos pela desmontagem da norma social em desalinhamento com o entendimento privado, nalgumas situações há enviesamentos sociais "pegajosos" que dificultam, em muito, uma completa remissão: empiricamente observa-se, ainda hoje, nas universidades americanas uma segregação informal dos alunos, em que os de cor não se misturam com os caucasianos. "Pese embora de ambos os lados haja a manifestação de desejo e de abertura à convivência com o outro grupo, os dois percepcionam (erradamente) que a contraparte não o quer, comportando-se de acordo com esse papel, perpetuando, deste modo, condutas segregacionistas.

Em segundo lugar, o peso da sociabilidade, isto é o desejo e necessidade do sentimento de pertença a um determinado grupo, reproduzindo-se assim comportamentos que são entendidos como a norma naquele universo social. Tal pode traduzir-se em pequenas coisas como a indumentária até à violação de direitos fundamentais como ataques a determinadas etnias, religiões, orientações sexuais, entre outras, inclusive como ritual de entrada para o grupo.

${ }^{8}$ RD.A. Prentice (20I2). 8 ess.

${ }^{9}$ D.A. Prentice (20|2). 11 .

${ }^{10}$ A. K. Woods (20I0). 65 ess.

"D.A. Prentice(20|2). 14. 
Em terceiro lugar, a dificuldade em se saber, em concreto, definir as próprias preferências, buscando para tal referências e auxílio na conduta dos outros, que passa a servir de âncora comportamental. Este tipo de razão ajuda a explicar condutas omissivas, por exemplo, em situações de acidentes ou de violação de direitos humanos, em que se age como um espectador, esperando-se para decidir como agir dentro de um leque de opções. Ora, se todos ou pelo menos a maioria espera para decidir, a inacção torna-se a regra e o status quo mantém-se. ${ }^{12}$

Estes fenómenos ajudam pois a explicar a razão pela qual a pessoa comum ficará parada a assistir a atrocidades, polariza comportamentos ou porque determinadas práticas violadoras dos direitos humanos se mantêm.

Por outras palavras, o poder das normas sociais influencia o comportamento individual mais do que o querido ou até percebido. Quatro estudos empíricos e/ou experimentais ajudam a prová-lo. ${ }^{13}$

Num estudo ${ }^{14}$ testando um folheto para pendurar na porta, quando perguntados sobre as razões que motivariam condutas pro-ambientais, os inquiridos declararam ser motivados, primeiramente, pela responsabilidade social e pela protecção ambiental, depois pela informação sobre o problema e por razões egoísticas (defesa do interesse próprio) e, por fim, muito abaixo, por normas sociais descritivas. ${ }^{15}$ Face às frases impressas que serviram de mote, apurou-se, no entanto, que os comportamentos revelavam uma outra hierarquia de incentivos: no curto prazo, prima a norma social, seguida do interesse próprio, da protecção ambiental, da responsabilidade social e da informação de controlo; no longo prazo, a norma social mantém a primazia, seguindose a protecção ambiental, a informação de controlo, o interesse próprio e a responsabilidade social.

Uma outra experiência, ${ }^{16}$ muito semelhante, sugere, tal-qualmente, a interferência comportamental das normas sociais. A utilização de folhetos nas portas com a indicação dos consumos energéticos dos vizinhos revela efeitos de crowding-in mas também de crowding-out, isto é, para aqueles que apresentam gastos superiores à média, a

${ }^{12}$ D.A. Prentice (2012). 12 ess.

${ }^{13}$ Ver, nos parágrafos seguintes, R. Saraiva (20 I5).

${ }^{14}$ J. Nolan [et al.] (2008). Ver também, N. Goldstein, R. B Cialdini, \& V. Griskevicius (2008).

${ }^{15} \mathrm{Na}$ experiência, cada lar recebe conselhos e informação, assim como um mote:

I. Poupe dinheiro poupando energia (interesse próprio)

2. Proteja o ambiente poupando energia (protecção ambiental)

3. Junte-se aos seus vizinhos na poupança de energia (norma social)

4.Faça a sua parte e poupe energia para as gerações futuras (responsabilidade social)

5. Poupe energia (informação de controlo)

${ }^{16}$ P. Schultz [et al.] (2007). 
informação sobre o comportamento alheio incute uma alteração das condutas no sentido de uma maior eficiência, já no caso contrário alimenta o desperdício num rebound effect. A correcção deste desvio alcança-se, porém, com o acrescento de um smile junto do valor do consumo. Aparentemente, o emoticon é interpretado como um sinal normativo. ${ }^{17}$

Num programa mais alargado conduzido pela empresa energética OPOWER, envolvendo cerca de 600 mil lares americanos informados, por via da sua factura, da conduta energética da vizinhança e com dicas de racionalização, verificou-se uma diminuição entre $1.11 \%$ a $2.78 \%$ dos consumos. A longo prazo, porém, estes resultados diminutos mas prometedores (afinal, com uma solução barata, facilmente exequível e socialmente aceitável consegue-se uma inversão, mesmo que não muito significativa, dos padrões de consumo) demonstram alguma inconsistência, não sendo claro se o efeito das normas sociais se desvanece com a adaptação progressiva dos agentes económicos. ${ }^{18}$ Ademais, as reacções divergem consoante as inclinações políticas, com liberais a responderem positivamente ao feedback social ao contrário dos mais conservadores. ${ }^{19}$

Os resultados, contudo, parecem mais sólidos e homogéneos num outro ensaio com folhetos em quartos de hotel com a diminuição em $25 \%$ das toalhas para lavar quando se recorre a normas sociais descritivas. ${ }^{20}$

Igualmente interessantes em matéria de implementação e defesa dos direitos humanos são as ilações que podem ser retiradas do jogo do ditador e do ultimato, que traduzem a importância da reciprocidade e de um sentido evolutivo-cultural e até natural de justiça e de experiências laboratoriais que revelam a punição dos batoteiros mesmo se com custos privados. Ora, se os cooperadores condicionais (i.e. sujeitos que estão dispostos a iniciar uma acção cooperativa quando estimam que os outros irão reciprocar e durante o tempo que consideram que parte dos outros irá colaborar) constituem uma parte significativa da população, ${ }^{2 !}$ é grande o potencial das normas sociais defensoras dos direitos humanos pela sua dimensão e função expressivas, ${ }^{22}$ sobretudo em contextos de identificação (em que o indivíduo se identifica pelas suas características com outros) e iterativos que fomentam a comunicação e em que se punem os free riders. Ou seja, as normas sociais (descritivas e injuntivas) podem ser verdadeiros motores de mudança para alinhar as condutas com os standards dos direitos humanos (o contrário, infelizmente, porém, como se viu, pode identicamente suceder).

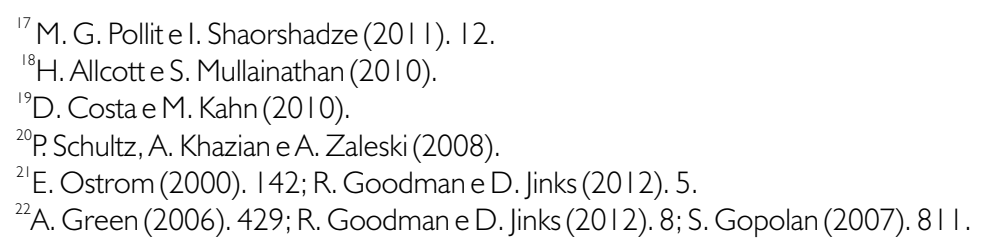


As normas sociais podem, deste forma, ser usadas para diminuir comportamentos negativos, fomentar comportamentos positivos, ou como meio de tradução entre culturas e ordens normativas (designadamente entre o Direito (concepção de direitos de apropriação ou de direitos humanos, entre outros) e a ordem social, que rege, de acordo com os trabalhos de Ostrom, várias comunidades indígenas, ou religiosa, em especial nos países submetidos à sharia). Por outras palavras, as normas sociais podem auxiliar na mudança de atitudes, crenças, representações e percepções erradas das condutas aceites, assim como da motivação através de pressão social, agindo sobre todos os membros do grupo para forçar um movimento colectivo corrector.

Neste sentido, as normas sociais servem, em primeiro lugar, para mudar a sinalização e os comportamentos percepcionados, por via (i) da saliência de que todos os membros do grupo (ou pelo menos a maioria) querem privadamente o mesmo tipo de conduta (ex. respeito dos direitos das mulheres) ou que querem algo diferente do socialmente percepcionado como aceite (ex. crimes de honra), ou (ii) da não saliência de comportamentos negativos (ex. não publicitação de ocupação (sem sanção) de terras indígenas).

Em segundo lugar, as normas sociais podem ser utilizadas para mudar a própria ideia de grupo, isto é dos seus limites, de quem lhe pertence ou não, face às dinâmicas intra e extra-grupo. Por exemplo, pode ser interessante modelar o entendimento dos fazendeiros sobre si próprios enquanto grupo separado dos indígenas - e enquanto tal com um papel social pré-determinado a representar - de modo a que se identifiquem com aqueles, nomeadamente como pertencendo ambos ao grupo mais amplo de tocantinenses ou de brasileiros.

Em terceiro lugar, as normas sociais podem servir para alavancar a sociabilidade, considerando, em particular, os fenómenos de aculturação e de inculturação através do mimetismo social tantas vezes observado, num efeito de manada que reproduz e alarga comportamentos. ${ }^{23}$ Aliás, este movimento é visível no próprio Direito, inclusive dos direitos humanos, com uma aproximação, primeiro lenta e depois exponencial, dos diferentes ordenamentos jurídicos. Afinal, uma esmagadora maioria de Estados, de fundo cultural diferente, assinou as convenções internacionais de direitos humanos.

problema, todavia, prende-se com a garantia de uma mudança sustentada e duradoura dos comportamentos, i.e. que não se fique por uma alteração pontual e de curto prazo mas que se perpetue.

\footnotetext{
${ }^{23}$ R. Goodman e D. Jinks (2004). 16 ess.
} 
Quatro aspectos devem, deste modo, ser ponderados.

Nunca é demais sublinhar a importância do acesso à informação e da educação, tanto por parte da população como das instituições, hoje potenciados positiva (e negativamente ${ }^{24}$ ) pelas redes sociais e pela denominada sociedade da informação. Estas constituem a base para a relevante promoção da discussão pública e participação nas decisões, numa garantia da liberdade de expressão e de um Estado de Direito democrático, de modo a se apurar e evidenciar as diferenças de opiniões e desmontar comportamentos negativos. Ademais, permitem, quanto a este último aspecto, através de um cuidado com a forma de comunicação de informação, alterar o balanço de uma análise custo-benefício para aqueles agentes que são mais racionais e cujas condutas são maximizadoras de utilidade. Posto de outra forma, para aqueles que valorizam (excessivamente) os benefícios económicos, mostra-se-lhes (pecuniariamente) as vantagens de respeito dos direitos humanos. Por exemplo, em questões de género, levar os homens, nomeadamente os maridos, a perceber as vantagens económicas (mas também familiares) de uma esposa educada e que trabalha fora de casa, aumentando assim os rendimentos familiares, as hipóteses de sucesso dos filhos e até o tempo de lazer do cônjuge. Ou seja, a discriminação de género é também penalizadora para o homem, até pelo papel limitativo e pré-determinado que lhe é atribuído. ${ }^{25}$

Note-se, porém, que a desconstrução por via da promoção da informação e do debate pode esbarrar numa potencial resistência associada ao receio da perda do elo de pertença e de identificação com o grupo ou de ausência de referencial, culminando na não supressão total da má norma. Para além do mais, nada garante que a nova norma seja melhor do que a anterior ou que o vazio normativo não cause efeitos piores ou que se acabe por afectar o quadro normativo geral em vez de se tratar de forma milimétrica o problema específico que há que resolver.

Num segundo momento, cabe alertar para a importância da norma descritiva pela sua função de âncora comportamental. $\bigcirc$ caso da Opower acima referido exemplifica bem o fenómeno de comparação comportamental relativamente aos "pares". Esta experiência poderia eventualmente ser transposta para o âmbito dos direitos humanos, por exemplo nas relações entre fazendeiros ou multinacionais e índios. Corre-se, todavia, o risco, já supra abordado, de conferir excessiva saliência a uma má conduta, alertando para a sua possibilidade e normalidade, provocando, deste modo, uma expulsão de (eventuais) boas condutas. ${ }^{26}$ Mais, a linha divisória entre este tipo de actuação correctora e a manipulação, como aconteceu na Alemanha nazi ou mais recentemente no Ruanda, assemelha-se muito ténue.

\footnotetext{
${ }^{24}$ A. K. Woods (2010). 6 I ess.

${ }^{25}$ J. Jütting e C. Morrisson (2005). 18 e 21 .

${ }^{26}$ R. Goodman e D. Jinks (20/2). 4-6.
} 
Em terceiro lugar, também as normas sociais injuntivas podem, com algumas reservas, constituir um meio para assegurar uma alteração sustentada de comportamentos. Recorde-se o contributo corrector do emoticon adicionado aos consumos energéticos e que, no fundo, traduz a (des)aprovação do grupo. $\bigcirc$ desenvolvimento e publicação de relatórios sobre o (in)cumprimento dos direitos humanos pode funcionar neste sentido, devendo-se não apenas apontar as violações mas igualmente louvar ou pelo menos apontar os progressos mas também a manutenção de comportamentos consentâneos com a protecção dos direitos humanos.

Por fim, num contexto competitivo em que diversos assuntos reclamam, de forma competitiva, a atenção e motivação, importa manter a saliência sobre a temática dos direitos humanos. ${ }^{27}$ Vários instrumentos, legais, sociais, económicos cognitivocomportamentais, entre outros, podem ser combinados para o efeito. Contudo, convém notar que a sua concertação requer arte pois, em determinados contextos e na ordem errada, excluem-se mutuamente. ${ }^{28}$ Recordem-se, designadamente, os exemplos aprendidos com o pagamento das doações de sangue, que afastou doadores pelo desaparecimento do significado e motivação moral e altruísta, ou da coima pecuniária para pais retardatários numa creche israelita que, ao alterar o enquadramento de social para de mercado, provocou o efeito contrário ao pretendido. $^{29}$

A compreensão da lei enquanto instrumento de garantia dos direitos humanos deve, deste modo, ser entendida nesta óptica situacional, até porque o Direito é contextual e contextualizado e não pode desprezar a sua aceitabilidade social sob pena das alterações que propõe não serem efectivadas. Veja-se, neste sentido, a já mencionada mais-valia da mudança da referência social ser feita internamente, como no caso marroquino citado, do uso do sabão no Gana ${ }^{30}$ ou do duelo nos Estados-Unidos. ${ }^{31}$ Ou seja, a solução de protecção dos direitos humanos é contextual. $\bigcirc$ que funciona no cenário A poderá não funcionar no cenário B. O conhecimento local e psicológico é fundamental. A cautela impera na utilização das normas sociais e na aplicação de instrumentos implementadores de uma cultura de direitos humanos

Aliás, e antes de concluir, às vezes o menos é mais. Por exemplo, a concentração da condenação nas violações menos graves em vez de se atacar sobretudo as mais gravosas. Pense-se na política do mayor Giuliani na cidade de Nova lorque, que

\footnotetext{
${ }^{27}$ D.A. Prentice (20|2). 21.

${ }^{28}$ R. Goodman e D. Jinks (20।2). 3 ess.

${ }^{29}$ U. Gneezy e A. Rustichini (2000).

${ }^{30}$ A. K. Woods $(2010) \cdot 54$.

${ }^{31}$ D.A. Prentice (20|2). 26-27.
} 


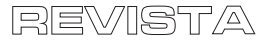

combatendo os crimes mais leves alterou o ponto de referência comportamental. Afinal, às vezes basta um pequeno empurrão na direcção certa, ou é só o que é possível, ou porque se evita, deste modo, que a mudança seja percepcionada e julgada como um sinal de fraqueza. ${ }^{32}$ Todavia, esta abordagem apenas funcionará se existir um fosso entre a norma social descritiva e injuntiva.

Em jeito de conclusão, para uma nova e melhor arquitectura da escolha, sublinhe-se que faltam estudos para perceber a dinâmica das normas sociais e as suas inter-relações com outras ordens normativas e sobre qual a melhor sequência e combinação entre instrumentos diversos para a garantia dos direitos humanos. A aplicação das normas sociais deve pois ser levada a cabo com moderação até pela alteração natural das preferências. Em suma, one size does not fit all.

Ademais, a ponderação do contexto social no (in)cumprimento dos direitos humanos introduz no debate uma maior flexibilização e aponta para uma não usual "moral" situacional e empírica contrária à tradição jurídica actual.

Deixa-se aqui, portanto, o mote para futuras reflexões nesta sede.

\section{REFERÊNCIAS}

ALLCOTT, H.; MULLAINATHAN, S. Behavioral Science and Energy Policy. Cambridge, M A : I d e a s 42 . $20 \mid 0$.

<http://ideas42.iq.harvard.edu/publications/behavioral_science_energy_policy > .

COSTA, D.; KAHN, M. Energy Conservation "Nudges" and Environmentalist Ideology: Evidence from a Randomized Residential Electricity Field Experiment, NBER Working Paper No. 15939, Cambridge, MA: National Bureau of Economic Research. 2010.

ELLICKSON, R. C. The market for social norms, American Law and Economic Review, n. 3.2001 .

GNEEZY, Uri; RUSTICHINI, Aldo. Pay enough or don't pay at all, Quarterly Journal of Economics. 2000.

GOODMAN, Roy; JINKS, Derek. Social mechanisms to promote international human rights: Complementary or contradictory?, New York University Law School, Public Law Research Papern. ${ }^{\circ}$ | I-74. 2012.

\footnotetext{
${ }^{32}$ R. Goodman e D. Jinks (20|2). 7.
} 
GOODMAN, Roy; JINKS, Derek. How to influence states: Socialization and international human rights law, The University of Chicago Law School, Public Law \& Legal Theory Working Paper n. ${ }^{\circ}$ 62. 2004.

GOLDSTEIN, N.; CIALDINI, R. B; GRIKEVICIUS, V. A room with a viewpoint: Using social norms to motivate environmental conservation in hotels, Journal of Consumer Research, 35. 2008.

GOPALAN, Sandeep. Alternative sanctions and social norms in international law: The case of Abu Ghraib, Michigan State Law Review, Vol. 785. 2007.

GREEN, Andrew. You can't pay them enough: subsidies, environmental law and social norms, Harvard Law Review, Vol. 30. 2006.

JÜTTING, Johannes; MORRISSON, Christian. Changing social institutions to improve the status of women in developing countries, OECD Policy Brief. 2005.

NOLAN, J. [et al.]. Normative social influence is underdetected, Personality and Social Psychology Bulletin, 34. 2008.

OSTROM, Elinor. Collective Action and the Evolution of Social Norms, The Journal of Economic Perspectives, Vol. I4, n. ${ }^{3}$, Verão. 2000.

POLLIT, Michael G.; SHAORSHADZE, Irina. The Role of Behavioural Economics in Energy and Climate Policy, University of Cambridge EPRG Working Paper n. ${ }^{\circ}$ I I 30. 2011 .

PRENTICE, Deborah A. The Psychology of Social Norms and the Promotion of Human Rights, Princeton University. 2012.

SARAIVA, Rute. Protecção ambiental e normas sociais. In Alexandra Aragão, Gisela Maria Bester e Gloriete Marques Alves Hilário (coord.) Direito e Ambiente para uma Democracia Sustentável - Diálogos multidisciplinares entre Portugal e Brasil, Instituto Memória, Curitiba. 2015. no prelo.

SCHULTZ, P. [et al.]. The constructive, destructive, and reconstructive power of social norms. Psychological Science, I 8 (5). 2007.

SCHULTZ, P.; KHAZIAN, A.; ZALESKI, A. Using normative social influence to promote environmental conservation among hotel guests, Social Influence, 3. 2008. 
SCOTT, R.E. The Limits of Behavioral Theories of Law and Social Norms, Virginia Law Review, Vol. 86. 2000.

VANDENBERGH, Michael P. Order without social norms: How personal norm activation can protect the environment, Vanderbilt University Law School, Public Law and Legal Theory Working Paper n. ${ }^{\circ}$ 05- 18. 2005.

WOODS, Andrew K. A Behavioral Approach to Human Rights, Harvard International Law Review, Vol. 51, n. I. 2010.

Recebido em: 27/05/20I5

Aprovado em: 16/1 I/2016 